\title{
Propulsion Health Management System Development for Affordable and Reliable Operation of Space Exploration Systems
}

Kevin J. Melcher

Glenn Research Center, Cleveland, Ohio

William A. Maul

Analex Corporation, Brook Park, Ohio

Sanjay Garg

Glenn Research Center, Cleveland, Ohio 


\section{NASA STI Program . . . in Profile}

Since its founding, NASA has been dedicated to the advancement of aeronautics and space science. The NASA Scientific and Technical Information (STI) program plays a key part in helping NASA maintain this important role.

The NASA STI Program operates under the auspices of the Agency Chief Information Officer. It collects, organizes, provides for archiving, and disseminates NASA's STI. The NASA STI program provides access to the NASA Aeronautics and Space Database and its public interface, the NASA Technical Reports Server, thus providing one of the largest collections of aeronautical and space science STI in the world. Results are published in both non-NASA channels and by NASA in the NASA STI Report Series, which includes the following report types:

- TECHNICAL PUBLICATION. Reports of completed research or a major significant phase of research that present the results of NASA programs and include extensive data or theoretical analysis. Includes compilations of significant scientific and technical data and information deemed to be of continuing reference value. NASA counterpart of peer-reviewed formal professional papers but has less stringent limitations on manuscript length and extent of graphic presentations.

- TECHNICAL MEMORANDUM. Scientific and technical findings that are preliminary or of specialized interest, e.g., quick release reports, working papers, and bibliographies that contain minimal annotation. Does not contain extensive analysis.

- CONTRACTOR REPORT. Scientific and technical findings by NASA-sponsored contractors and grantees.
- CONFERENCE PUBLICATION. Collected papers from scientific and technical conferences, symposia, seminars, or other meetings sponsored or cosponsored by NASA.

- SPECIAL PUBLICATION. Scientific, technical, or historical information from NASA programs, projects, and missions, often concerned with subjects having substantial public interest.

- TECHNICAL TRANSLATION. Englishlanguage translations of foreign scientific and technical material pertinent to NASA's mission.

Specialized services also include creating custom thesauri, building customized databases, organizing and publishing research results.

For more information about the NASA STI program, see the following:

- Access the NASA STI program home page at http://www.sti.nasa.gov

- E-mail your question via the Internet to help@sti.nasa.gov

- Fax your question to the NASA STI Help Desk at 301-621-0134

- Telephone the NASA STI Help Desk at 301-621-0390

- Write to: NASA Center for AeroSpace Information (CASI) 7115 Standard Drive Hanover, MD 21076-1320 


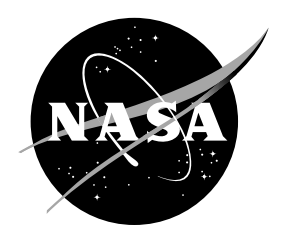

\section{Propulsion Health Management System Development for Affordable and Reliable Operation of Space Exploration Systems}

Kevin J. Melcher

Glenn Research Center, Cleveland, Ohio

William A. Maul

Analex Corporation, Brook Park, Ohio

Sanjay Garg

Glenn Research Center, Cleveland, Ohio

Prepared for the

Space 2007

sponsored by the American Institute of Aeronautics and Astronautics Long Beach, California, September 18-20, 2007

National Aeronautics and

Space Administration

Glenn Research Center

Cleveland, Ohio 44135 


\section{Acknowledgments}

The authors would like to thank and acknowledge Dr. Louis M. Santi, currently of the Jacobs, ESTS Group, in Huntsville Alabama, for his contributions to this research. Discussions and brain-storming activities conducted with him as a member of our health management group have laid the foundations for the PHMS roadmap presented here.

Trade names and trademarks are used in this report for identification only. Their usage does not constitute an official endorsement, either expressed or implied, by the National Aeronautics and Space Administration.

Level of Review: This material has been technically reviewed by technical management.

Available from

NASA Center for Aerospace Information 7115 Standard Drive

Hanover, MD 21076-1320
National Technical Information Service 5285 Port Royal Road Springfield, VA 22161 


\title{
Propulsion Health Management System Development for Affordable and Reliable Operation of Space Exploration Systems
}

\author{
Kevin J. Melcher \\ National Aeronautics and Space Administration \\ Glenn Research Center \\ Cleveland, Ohio 44135 \\ William A. Maul \\ Analex Corporation \\ Brook Park, Ohio 44142 \\ Sanjay Garg \\ National Aeronautics and Space Administration \\ Glenn Research Center \\ Cleveland, Ohio 44135
}

\begin{abstract}
The constraints of future Exploration Missions will require unique integrated system health management capabilities throughout the mission. An ambitious launch schedule, human-rating requirements, long quiescent periods, limited human access for repair or replacement, and long communication delays, all require an integrated approach to health management that can span distinct, yet interdependent vehicle subsystems, anticipate failure states, provide autonomous remediation and support the Exploration Mission from beginning to end. Propulsion is a critical part of any space exploration mission, and monitoring the health of the propulsion system is an integral part of assuring mission safety and success. Health management is a somewhat ubiquitous technology that encompasses a large spectrum of physical components and logical processes. For this reason, it is essential to develop a systematic plan for propulsion health management system development. This paper provides a high-level perspective of propulsion health management systems, and describes a logical approach for the future planning and early development that are crucial to planned space exploration programs. It also presents an overall approach, or roadmap, for propulsion health management system development and a discussion of the associated roadblocks and challenges.
\end{abstract}

\section{Introduction}

Propulsion is a vital part of any space exploration mission, starting from launch vehicles, to upperstage-to-orbit or in-space propulsion. Reliable and safe operation of the various propulsion systems is critical to achieving mission success; it must, however, be performed at an acceptable cost. Monitoring the health of the propulsion system and other subsystems is an integral part of assuring mission safety and success. The current paradigm to such monitoring consists mainly of having a suite of sensors on-board which can sense physical quantities related to the performance and/or operational status of various propulsion-related components. Typically only safety critical decisions are made on-board with limited remediation such as engine shut down; or, automated redundancy management is designed into the systems where backup functional components would be activated in the event of faults. Some of the information is telemetered to the ground for review and analysis by teams of experts. These ground-based teams oversee the on-board monitoring system and react to "off-nominal" situations, performing diagnostic analysis and remediation to ensure safety and mission success. 
This current approach to "ground-based diagnostics and remediation" requires a readily available team of experts; each highly trained in a particular area. It is very human intensive and costly in terms of continued operations. In addition, it tends to be quite conservative with regard to safety - the result of avoiding negative consequences due to human error. This approach is also restricted by the need for communication between space vehicle and earth - there can be substantial time delays associated with this communication which can result in catastrophic failures if any safety critical conditions are not diagnosed in a timely manner. With the advancement of sensor technology and computer capability, more extensive signal processing and diagnostic functions offer potential solutions to complex system health management problems. For space propulsion systems, effective propulsion health management systems (PHMS) must be available early in the program to support the design of propulsion systems that are safe, reliable and highly autonomous. Early PHMS availability is also needed to promote design for affordable operations; increased knowledge of functional health provided by PHMS supports construction of more efficient operations infrastructure. However, lack of early PHMS inclusion in the system design process could result in retrofitting health management systems; thereby increasing program cost and risk due to increased instrumentation and computational complexity.

Health management is a somewhat ubiquitous technology that encompasses a large spectrum of physical components and logical processes. For this reason, it is essential to develop a systematic plan for PHMS development. The objective of this paper is to provide a high level perspective of propulsion health management systems, and to describe a logical approach for future planning and early development crucial to support of planned space exploration programs. Discussion will begin with a description of a PHMS roadmap that breaks down the system into a number of products specific to PHMS. Important lessons learned from previous aerospace and aeronautical engine health management programs are then described. These lessons shape perspectives of where propulsion health management systems are now, and serve as a natural springboard for discussion of where PHMS development needs to go. Finally, the logical basis for treating propulsion health management as a system-centered solution that impacts not only operations, but also design and robust knowledge capture, is then presented.

\section{PHM Roadmap Overview}

Because of the high energy and large risk, propulsion systems are often focal points for health management (HM) activities and, therefore, aerospace programs invest substantial resources in HM technology development and application. Optimum performance and effectiveness of a HM system is achieved when its development coincides with the development of the system whose health it is being tasked to manage (ref. 1). It is much less effective and efficient when it is implemented after the fact. In fact, the HM system design, like the monitored system design, is a continuous, iterative process that requires a symbiotic relationship with the monitored system. As the monitored system design becomes more refined and focused, the HM system can also be refined; and as the HM system develops, it can impact the monitored system design and operation. The iterative nature of this design process also requires a symbiotic relationship between the subsystem developers (i.e., domain experts) and the HM system developers. These two groups of experts must work together cooperatively if the final design is to meet requirements for performance, operation, and health assessment.

In general, the PHMS development process requires a thorough understanding of the system being managed. Knowledge acquisition from domain experts is essential in establishing the scope of a PHMS. A clear set of system requirements and operations concept are some of the first essential elements. A Failure Modes and Effects Criticality Analysis must be performed to identify the critical faults and document how those faults manifest themselves in the system. Also, when development of a PHMS is incorporated early in the system design, little, if any, test data is available and therefore numerical models of the system are essential. These system models must have sufficient detail and complexity so that they provide a sound basis for developing and testing the required HM system.

At the same time, the developing HM technologies can impact the monitored system design. Identified critical failure modes may only be covered through the HM system if sufficient sensor data is 
available. In some cases, sensors may need to be added to the system to enable detection or provide sufficient redundancy for robust HM operation. Failure modes beyond current PHMS capabilities may force system re-design or impact operation in order to remove or mitigate the risk to the propulsion system. System designs which have rigorous fault/hazard analyses and HM development processes will anticipate and address potential problems earlier in the design cycles where resolutions will not require costly retrofits and delays.

Focusing on the design requirements for the monitored system, as it pertains to development of the PHMS, the elements of the development process may be broken-down as follows:

- Sensor Selection

- Data Validation

- Fault Detection

- Fault Isolation

- Information Fusion

- Prognostics

- Verification and Validation

Here, it should be noted that, beyond the domain of the PHMS, this design approach and its elements are characteristic of a more general HM system that can readily be applied to other subsystems.

Figure 1 illustrates the process for developing a PHMS within the propulsion system design and development process. Each of the previously given elements are listed within the diagnostic/prognostic functions section, except for sensor selection and verification and validation which are solely design elements. Note the intentional use of a bus, rather than top-to-bottom data through-flow. The data bus was included here for two reasons. First, it generalizes the discussion by minimizing the focus on data flow which can be system dependent. A given PHMS will be designed to meet system specific requirements,



Figure 1.-Propulsion health management system design and development process. 
and all of the elements shown may not be needed or desired. By providing a general path for data flow, PHMS elements can be removed from or incorporated into this structure without re-routing the data flow. Second, it is also illustrative of the fact that elements of the PHMS system may not necessarily operate sequentially, that is, data in the PHMS may be available to the elements as needed rather than passed from one element to the next.

\section{PHMS Roadmap Elements}

In this section, each of the PHMS roadmap elements are discussed. In general, the discussion for each element includes: element definition, motivation, benefits, prior application with lessons learned, and challenges.

Before proceeding with the individual discussions, it is constructive to point out that clear boundaries between the PHMS elements do not exist. In fact, although figure 1 shows each PHMS element as a distinct entity, there can be significant overlap. For example, Data Validation, which detects and isolates failures in sensors, could be considered a subset of Fault Detection and Fault Isolation. And while Fault Detection can stand alone, it is clearly a crucial and defining element for the Fault Isolation and Prognostics technologies. Despite this overlap between the elements, for the purposes of this discussion, it is useful to address technology capabilities and challenges for each element individually.

\section{Sensor Selection}

Sensor data are the basis for evaluating the performance of any complex system; and careful selection and implementation of sensors is critical to enable high fidelity system health assessment. The purpose of the sensor selection process is to identify sensors that will fulfill requirements for health assessment of the monitored system while optimally meeting the design constraints. The sensor selection process should allow the designer to optimize such things as operational costs (e.g., purchase, installation, and maintenance), weight, and reliability in addition to health assessment performance. Additionally, optimization-based sensor selection processes can be used to prioritize the funding and development of new sensors. This would be accomplished by characterizing sensors proposed for development, adding them to the candidate sensor suites, then evaluating the results of the selection and optimization process. Prioritization could then be based in part on whether or not a given sensor is identified with an optimal sensor suite. This approach can provide managers with a tool for prioritizing the distribution of limited research and development funds.

Sensor selection is not unique to propulsion health assessment. In many technology areas, substantial research has been conducted to achieve optimum sensor and actuator placement within a given system (refs. 2 and 3). To meet the goal of optimal sensor placement, much of the associated research has focused on the establishment of proper performance and control design metrics and the development of techniques to optimize the solution search process.

References 3 and 4 present one sensor selection process named the Systematic Sensor Selection Strategy (S4). The S4 is a model-based procedure for systematically and quantitatively selecting an optimal sensor suite to provide overall health assessment of a given host system. The S4 procedure, shown in figure 2, has been applied to the Rocketdyne RS-83 and RS-84 boost stage liquid rocket engines and the Space Shuttle Main engines (SSMEs). In each case, the S4 demonstrated the ability to direct sensor selection decisions based on available system failure information and design constraints imposed on the process. Pratt \& Whitney Rocketdyne has continued to employ this approach on their current J-2X engine design for the NASA Constellation program.

S4 can be logically partitioned into three major subdivisions: the knowledge base, the down-select iteration, and the final selection analysis. The knowledge base consists of system design information and heritage experience together with a focus on components with health implications. The sensor suite downselection process identifies a group of sensors that provide good fault detection and isolation for targeted fault scenarios. This process is composed of three basic components: a system health diagnostic model, a 




Figure 2.-Procedure for Systematic Sensor Selection Strategy (S4).

merit algorithm, and a selection algorithm. In the final selection analysis, a statistical evaluation algorithm provides the final robustness test for each down-selected sensor suite.

Though this systematic sensor selection process was developed to enhance design phase planning and preparation for space propulsion health management, the S4 process can also be applied to a broad range of non-propulsion health management systems (e.g., power, communications, and fluid storage/feed systems) that are part of the NASA Exploration Systems architecture.

Regardless of the applied methodology, the sensor selection element should be flexible and applicable in several areas.

- Able to incorporate the best system design information available throughout the design cycle of the monitored system.

- Applicable to multiple types of systems (e.g., propulsion, electrical, hydraulic, etc.) and heterogeneous sensor networks (e.g., pressures, temperature, accelerometers, etc.)

- Able to incorporate weighting factors that represent both fault criticality and sensor costs.

- Applicable across various phases of system operation (e.g., pre-launch, flight, quiescence, shutdown, post-flight.)

- Modular to handle various evaluation and optimization techniques.

There are a variety of challenges associated with optimization of sensor suites. One challenge is the lack of models and health data early in the design process when sensor selection can provide the most benefit to the design process. Another challenge is balancing the need to have metrics functions that are well understood and easily defended against the desire to reach a globally optimal result. The first objective can yield relatively simple metric functions that produce suboptimal results; while the later objective can result in a poorly understood, complex, computationally-intensive, multi-dimensional, and potentially, over-constrained search space. 


\section{Data Validation}

Data validation is the process of analyzing sensor signals to insure that the data accurately represents the system state being measured. Data validation is an important element in the overall health assessment process as it can prevent safety system false alarms, unnecessary shutdowns, and improper system responses by ensuring that automated health management systems "reason" with valid (or qualified) data. Proper fault detection and isolation can only be performed when information provided by the sensors is valid.

As shown in figure 3, conventional techniques, such as limit checks, can identify hard sensor failures, while more advanced techniques (e.g., neural networks (ref. 5), model-based analytical redundancy (ref. 6), Kalman filters (ref. 7) and wavelets (ref. 8) have been applied to detect subtle or soft sensor failures, such as drift and noise. One such project developed an advanced sensor validation technology utilizing analytical redundancy with a Bayesian Belief network to provide real-time solutions for RS-83 and RS-84 propulsion systems (ref. 9). The analytical redundancy relationships between sensors in the engine were used to establish a belief network that would identify faulty sensors and provide a quantitative confidence measure for the identified sensor faults. The result of this effort is contained within a commercially available software suite, the Data Quality Validation Studio produced by Expert Microsystems, Inc. More recently, data validation is being incorporated into the design of the abort system for Ares I, NASA's next manned launch vehicle. There, it will provide for the safety of the crew by identifying faulty sensor data before they are used in critical operational decisions such as abort.

Data validation is vital for all systems, because system performance evaluation and system health assessment rely primarily on sensor information. For Exploration Systems Missions where automation and remediation are based exclusively on sensor data and limited human input, advancement of these technologies to ensure optimum implementation, development and certification is required. While conventional approaches have a legacy of implementation, more advanced approaches that focus on subtle sensor failures must demonstrate the ability to perform in the presence of multiple sensor failures and common-cause sensor failures. These advanced systems must also be prepared to face the challenge of avoiding misdiagnosis during system component failures, as well as, detecting the failure of feedback sensors in closed-loop control systems.

\section{Fault Detection}

Fault detection is basically the determination that something is awry with the system functionality. In this PHMS roadmap, it is focused solely on diagnosing system, rather than sensor, behavior. The detection portion of the PHMS must be capable of distinguishing nominal from truly anomalous conditions. Fault detection typically works hand-in-glove with fault isolation, as fault detection is most



Figure 3.-High-level view of data validation. 
effective when the fault can be isolated to a specific component or cause. Together, fault detection and isolation provide a basis for remediation that can result in a variety of scenarios from successful completion of the mission to a crew-saving abort sequence.

There are many detection techniques available. Some address specific system faults while others will monitor the system as a whole, using a model-based approach. Implementation will depend on the extent of understanding of the nominal propulsion system functions. Santi (ref. 4) and Butas (ref. 10) proposed an approach where specific system health parameters from available simulations are extracted to establish a fault data reconciliation matrix. Observations are then processed utilizing this matrix to detect and identify the anomaly.

If the system functions are unknown or uncertain to a great extent, then empirical approaches may be required. These approaches may include the application of data mining techniques to historical data to develop complex indicators of previously undiscovered relationships among available observations and the fault events (ref. 11). Upon detection and identification of events within the historical archives, algorithms can be developed to specifically monitor for those precursors that identify specific failure conditions. Another empirical approach taken by researchers is to define the nominal system operating envelope by using statistical methods, neural networks (ref. 12), radial-basis networks (ref. 13), or other empirically derived models (ref. 14), with detection being any observation statistically beyond the defined boundaries.

Fault detection technology requires an understanding of the monitored system and the potential modes of failure. Merely announcing an anomalous event is not sufficient; there must be a correlation of that event to some failure condition of the system, otherwise the detection is merely an academic exercise. Current detection processes called "redlines" are set on certain system parameters. When exceeded they indicate that system is experiencing a physical state beyond its safety design constraints. The redline detection does not necessarily indicate what is causing the failure, only that one is occurring. Advanced detection techniques may be involved in monitoring key health specific parameters or may need to be combined with diagnostic analysis to identify a specific failure condition. Doing so may enable various response activities that could allow the mission to continue.

One key challenge in this technology field is the acquisition of system and failure information. Especially early in the system design, there is limited domain knowledge and what is available is often inferred from other related or similar systems. Also due to the destructive nature of the fault conditions for propulsion systems, there is often little failure data sufficient to characterize the system response to those failures. Therefore verification and validation is often via simulation and dependent on simulation fidelity.

Another challenge area is the balance between missed detections and false alarms. Missed detections or detections delayed due to uncertainty could result in catastrophe; but a false alarm which forces the system to respond to a nonexistent condition can also lead to disastrous consequences along with a loss of confidence in the detection system. The detection methods must be established with a high level of confidence in proper detection and still enable a timely response to the situation.

\section{Fault Isolation}

We define fault isolation as the capability to distinguish between failure signatures, thus characterizing the failure condition to a particular faulty component or cause. In general, once an anomaly is detected the PHMS must identify the failure to ensure proper response to the condition. That is, unless the detection is a direct limit (e.g., redline limit) of the physical system or an indication of loss of structural integrity (e.g., breakwire indication) which requires an immediate single response. Fault isolation is the further resolution of the fault detection results to distinguish between various failures or failure groups. This resolution is only necessary when the proper identification of a fault affects the system response or remediation strategy. Isolation is not required when groups of failure modes have similar fault signatures with the same remediation strategy. 
Similar to the development of the fault detection process, fault isolation requires an understanding of the monitored system and the potential modes of failure, as well as, the distinguishing characteristics between failure modes that require different system responses. Fault isolation can be performed in a number of ways, e.g., using rule-based reasoning (ref. 15), model-based reasoning (ref. 3), or a hybrid architecture (ref. 16) that utilizes both rule-based and model-based analysis for fault identification and isolation.

One example of a demonstrated fault isolation system was the Propulsion IVHM Technology Experiment (PITEX) system. PITEX is a real-time model-based diagnostic system for the main propulsion system of the X-34 reusable launch vehicle (ref. 17). This diagnostic system was demonstrated in a simulation-based environment that used detailed models of the propulsion subsystem to generate nominal and failure data during the captive carry operational phase - the most safety-critical portion of the X-34 flight. Since no system-level testing of the X-34 Main Propulsion System (MPS) was performed, these simulated data were used to develop and demonstrate the software system. To accomplish the demonstration, advanced diagnostic and signal processing algorithms were developed and successfully tested in real-time on flight-like hardware.

Fault isolation capability must also be able to utilize heterogeneous pieces of information and data. Because direct measurements from the failed component are often unavailable, indirect measurements must be used to infer the condition. The impact the failed component has across the system is therefore combined into a deductive chain of reasoning that should point to the situation at hand. To arrive at an acceptable isolation solution, data fusion technologies (discussed in the following section) may be required so that isolation algorithms can use health-related data from measuring systems that do not align in time. In addition, alternative strings of confirming information increase the confidence in the final isolation analysis, and make the PHMS robust to loss of data due to sensor fault or communication loss.

The challenge of fault isolation technology is similar to that of fault detection with respect to the availability of system failure information. The lack of fault data makes verification and validation difficult and reliant on simulation of the faults. Due to this, sophisticated fault isolation strategies often lack confidence at the program level and are not, therefore, incorporated into on-board flight software.

\section{Information Fusion}

Information fusion is a cross-cutting technology that aligns data from similar and disparate sources in time and uses those data to perform higher-level system diagnosis. Often information from one subsystem must be fused with external pieces of data in order to establish a complete picture of the events. Even within subsystems, distinct instrumentation networks (e.g., accelerometers and flow-path sensors) result in disjointed bits of information that could be correlated to increase decision confidence. Data Fusion is an enabling technology for long duration missions where self diagnosis of very complex systems may be the difference between mission success and failure.

An example of research to implement information fusion technology occurred under NASA's Aviation Safety and Security Program, where NASA and Pratt \& Whitney collaborated to develop Information Fusion technologies (refs. 18 and 19). A wealth of aircraft turbine engine data is available from a variety of sources including on-board sensor measurements, operating histories, and component models. The challenge is how to maximize the meaningful information extracted from these disparate data sources to obtain enhanced diagnostic and prognostic information regarding the health and condition of the engine. To address this challenge, NASA and Pratt \& Whitney have developed the modular hierarchical information fusion architecture shown in figure 4 . The efficacy of this architecture was demonstrated through the fusion of two gas path analysis algorithms, the Enhanced Self-Tuning Onboard Real-time Model (eSTORM) and a neural network-based Gas Path Anomaly Detector (GPAD). This fusion allowed the system to detect and isolate both sensor and component faults. Furthermore, once a sensor fault was detected, it was accommodated (i.e., remediation strategy) by replacing the faulty physical measurement with an estimated value. This allowed the system to continue to accurately estimate component performance even in the presence of a sensor fault. 




Figure 4.-Data fusion architecture developed for the demonstration of available C-17 aircraft flight data (ref. 19).

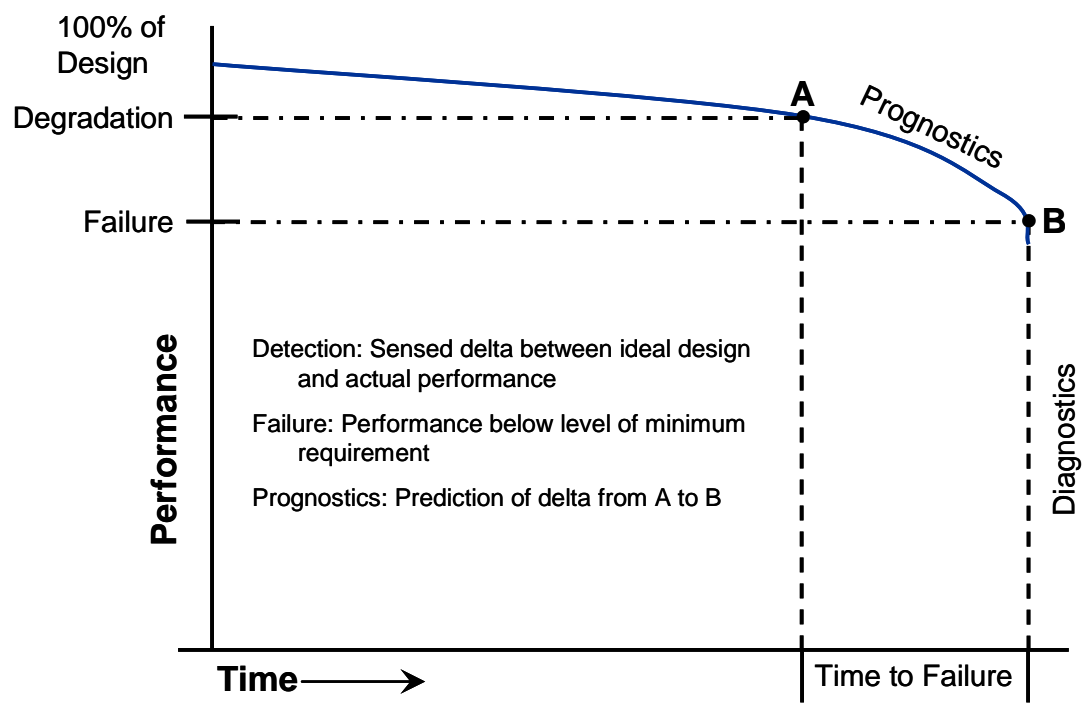

Figure 5.-Distinguishing diagnostics from prognostics.

\section{Prognostics}

Prognostic analyses, as the final level of inference, incorporate much of the previously discussed technologies and extends the analyses to define the life usage and remaining life of a system or component. Beyond the effort of early fault detection and isolation, prognostics attempts to quantify the remaining time that the system function will be available. To differentiate prognostics from diagnostics, Smith (ref. 20) uses a diagram similar to that shown in figure 5. Here, diagnostic analysis takes place after a failure has occurred, while prognostic analysis occurs prior to failure.

Prognostic analyses can be separated into either near-term prognostics or far-term prognostics. Reference 21 provides a survey of current prognostics activities within the aeronautical and aerospace 
fields. Near-term prognostics are the ability to determine the remaining time available to the system before the failure reaches a defined catastrophic level. Often this catastrophic level is that where the failure can no longer be tolerated by the system, remediation is useless and the result will be loss of mission and/or loss of crew. Near-term prognostics are used in the real-time, on-line mode and provide the response system with an indication of how much time remains before it must respond to a given situation. Baseline prognostics may merely be a predefined time allocation from initial detection until catastrophic condition based upon historical data or simulation analysis. More sophisticated prognostic strategies may be capable of updating the projected remaining time based on progression of the failure; of course, this additional capability requires a thorough understanding of relevant failure mechanisms.

Long-term prognostics provide system health assessment for maintenance scheduling and logistics support. This analysis does not require real-time, on-line processing and is based on projected performance of the system. While immediate remediation may not result from this analysis, immediate planning may. This planning may indicate a need for repair prior to the next scheduled activity involving the component; or, it may require an alteration in mission to handle the change in performance of the failing component. While the failures addressed here are not immediately life-threatening, for long duration missions to the Moon or Mars, they could have devastating results if not properly addressed. An example of this long-term prognostics development would be the Air Force's Joint Strike Fighter program (ref. 22), where the driver for the technology development is in fleet logistics, low life cycle costs, opportunistic maintenance and quick turnaround times.

As reported in reference 21, development and implementation for prognostic systems had been very limited. Issues of data availability for development and testing of this technology are even more severe than the other PHMS elements. Offering the ability to detect and isolate a fault condition requires a high level of verification to instill confidence in the PHMS output; adding the additional layer of sophistication required to project the fault progression will greatly exacerbate that verification effort.

\section{PHMS Verification and Validation}

Verification and validation are critical to the design and implementation of any flight software, including PHMS. Diagnostic algorithms and the tools used to develop them must be certified to satisfy the systems requirements; certified in their development process and in their performance. The diagnostic system itself should minimize its negative impact on the system and provide a substantial overall benefit. In other words the health management system should be resolving faults, not creating faults.

Brown (ref. 23) develops a set of requirements that diagnostic systems should aspire to. These include the ability to distinguish between nominal and anomalous operation (Fault Detection), the ability to distinguish between failure modes (Fault Isolation) and robustness to nominal system variations and external influences, such as sensor faults. Additionally, the requirement of timeliness should be added to ensure that the diagnostic performance provides sufficient time for the system to respond. Also the PHMS should demonstrate the ability to perform within system resource requirements, computer processing units and memory, and robustness to any resource stressed situations. Finally, the PHMS should be able to recover or restart from a power or data interruption with minimal impact to the health assessment performance of the system.

All of these PHMS requirements require significant data for development, testing and demonstration. Because of safety and program constraints, propulsion systems lack significant failure data; historically there have been no test programs where faults were intentionally inserted into flight or flight-like systems to determine the fault progression and system response. Instead, failure data is only coincidentally available from performance testing or flights, or from simulation. Therefore simulation testing will be a dominant capability to develop to support the PHMS verification and validation process. Pecheur (ref. 24) surveyed several diagnostic system verification and validation methodologies and each relied heavily upon simulation capabilities. To that end, simulation test beds, similar to the data qualification test bed implemented by Sowers (ref. 25), must be developed along with high fidelity simulations of the monitored system. 


\section{PHMS Impacts}

Propulsion systems provide a critical function for any space vehicle. However because of their volatile nature, propulsion system-related failures are generally severe and result in extremely adverse consequences. In addition, propulsion systems can not be treated as a separate disjointed element from the rest of the vehicle. Failure conditions from the propulsion element can be felt throughout other subsystems, e.g., structure, power and avionics. For the proper evaluation of propulsion health, it is important that all available and pertinent pieces of information from the vehicle are available. In addition, propulsion systems are complex and cannot easily be segmented into distinct components and treated separately for health assessment purposes. Propulsion systems are often complex elements with various feedback paths that faults conditions may impact. Therefore the entire propulsion system should be diagnosed by the PHMS.

In studies of aeronautical and space vehicles, propulsion failures are among the most prevalent and catastrophic of all the system failures. SAIC (ref. 26), reporting in a probabilistic risk assessment of the Shuttle, indicated a risk dominance of propulsion systems. Of the top 20 risk-contributing accident sequences, thirteen were associated with the Space Shuttle Main Engines or the Solid Rocket Boosters. Therefore, the ability to resolve and reconcile these failures has a very large impact on the overall system design. It is extremely important that PHMS design considerations are initiated at the very beginning of the system design analysis. Utilizing available PHMS technologies in the same manner as available control and sensor technologies when assessing the system design will enable a safe and reliable design. Specific impact areas include enhanced autonomous control in response to anomaly conditions, improved operational planning, cost effective maintenance for cause, informed design requirements, and more efficient test program planning.

\section{Concluding Remarks}

Health assessment of propulsion systems is crucial for the safe, reliable operation of any space vehicle. PHMS must be involved early in the system design process to take advantage of any potential benefit of the available technologies and avoid retro-fit costs. This paper identified a potential PHMS roadmap, breaking down and describing potential technology areas that provide building blocks for a PHMS. These technologies are not independent and distinct of each other and often require each other in order to provide the overall PHMS safety and reliable capability. In addition to the development of the diagnostic strategies, development of support elements such as system simulations and V\&V test-beds, must be considered in the PHMS roadmap plan.

\section{References}

1. Zuniga, F.A., et al., Integrated Systems Health Management for Exploration Systems, AIAA-20052586, 1st Space Exploration Conference, Orlando, Florida, January 30—February 1, 2005.

2. Padula, S. and Kincaid, R., Optimization Strategies for Sensor and Actuator Placement, NASA TM1999-209126, April, 1999.

3. Maul, W., et al., Sensor Selection and Optimization for Health Assessment of Aerospace Systems, AIAA Infotech@Aerospace 2007, Rohnert Park, California, May, 2007.

4. Santi, L., et al., Optimal Sensor Selection for Health Monitoring Systems, 41st Joint Propulsion Conference and Exhibit, AIAA-2005-4485, July 2005.

5. Guo, T.-H., et al., Sensor Failure Detection and Recovery by Neural Networks, IJCNN-91-Seattle International Joint Conference on Neural Networks, July 1991.

6. Maul, W., et al., Sensor Data Qualification for Autonomous Operation of Space Systems, American Association for Artificial Intelligence (AAAI) 2006 Fall Symposium-Spacecraft Autonomy, Washington, D.C., October, 2006. 
7. Kobayashi, T. et al., Evaluation of an Enhanced Bank of Kalman Filters for In-Flight Aircraft Engine Sensor Fault Diagnostics, ASME Paper GT2004-53640 (NASA/TM-2004-213203, ARL-TR3252).

8. Ma, J., et al., Wavelet Transformation Based Sensor Validation, IEE Colloquium on Intelligent and Self-Validating Sensors, no. 160, June, 1999.

9. Bickford, R. L., et al., Real-Time Flight Data Validation for Rocket Engines, 32nd Joint Propulsion Conference, AIAA/ASME/SAE/ASEE, 96-2827, July 1996.

10. Butas, J., et al., Rocket Engine Health Monitoring Using a Model-Based Approach, Proceedings of the 37th AIAA/ASME/SAE/ASEE Joint Propulsion Conference, Salt Lake City, Utah, June 2001.

11. Schwabacher, M., et al., Unsupervised Anomaly Detection for Liquid-Fueled Rocket Propulsion Health Monitoring, AIAA InfoTech Aerospace Conference, Rohnert Park, California, May, 2007.

12. Meyer, C., et al., SSME Mainstage Sensor Signal Approximation using Feedforward Neural Networks, 4th Annual Space System Health Management Technology Conference, November, 1992.

13. Wheeler, K., et al., Space Shuttle Main Engine Sensor Modeling Using Radial-Basis-Function Neural Networks, Journal of Spacecraft and Rockets, vol. 31, no. 6, Nov-Dec, 1994, pp. 1054-1060.

14. Maul, W., Multi-sensor Analysis Techniques for SSME Safety Monitoring, AIAA-90-1990, AIAA/ASME/SAE/ASEE 26th Joint Propulsion Conference, Orlando, FL, July 16-18, 1990.

15. Bickmore, T. et al., A Qualitative Approach to Systemic Diagnosis of the SSME, AIAA-93-0405, 31st Aerospace Sciences Meeting, Reno, NV, January 11-14, 1993.

16. Merrill, W., et al., Integrated Health Monitoring and Controls for rocket Engines, NASA TM105763, 1992.

17. Maul, W. A., et al., Addressing the Real-World Challenges in the Development of Propulsion IVHM Technology Experiment (PITEX), First Intelligent Systems Technical Conference, AIAA, September 2004.

18. Volponi, A., et al., Development of an Information Fusion System for Engine Diagnostics and Health Management, 39th Combustion/27th Airbreathing Propulsion/21st Propulsion Systems Hazards/3rd Modeling and Simulation Joint JANNAF Subcommittee Meeting Colorado Springs, Colorado, December 2003.

19. Volponi, A., Data Fusion for Enhanced Aircraft Engine Prognostics and Health Management, NASA/CR-2005-214055, 2005.

20. Smith, G, et al, Logistics for the Joint Strike Fighter-It Ain't Business as Usual, Air Force Journal of Logistics, vol. XXIII, no. 1, pp. 14-18.

21. Schwabacher, M., A Survey of Data-Driven Prognostics, AIAA InfoTech Aerospace, Arlington, Virginia, September, 2005.

22. Smith, G., Schroeder, J., Navarro, S. and Haldeman, D., Development of a Prognostics \& Health Management Capability for the Joint Strike Fighter, Proceedings of the 1997 IEEE AUTOTESTCON Conference, Anaheim, CA, September 1997, pp. 676-682.

23. Brown, S.A. and Pecheur, C, Model-Based Verification of Diagnostic Systems, 2nd JANNAF Modeling and Simulation Subcommittee Meeting/Volume 1, pp. 225-233, CPIA-Publ-715-Vol-1, April 2002.

24. Pecheur, C. and Nelson, S., Survey of NASA V and V Processes/Methods, NASA/CR—2002-21140, April 2002.

25. Sowers, T.S., Santi, L.M, and Bickford, R.L., Performance Evaluation of a Data Validation System, NASA/CR-2005-213813, AIAA-2005-4486, 2005.

26. Fragola, J., Probabilistic Risk Assessment of the Space Shuttle. Phase 3: A Study of the Potential of Losing the Vehicle During Nominal Operation, Volume 1 Final Report, NASA-CR-197808, 1995. 


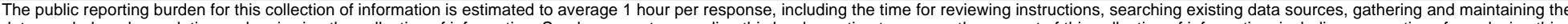

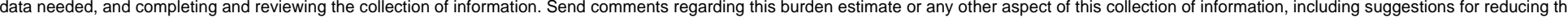

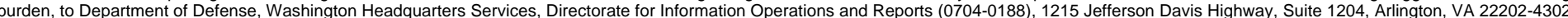

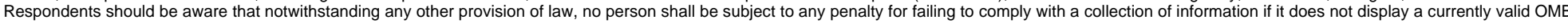
control number.

PLEASE DO NOT RETURN YOUR FORM TO THE ABOVE ADDRESS.

\section{REPORT DATE (DD-MM-YYYY) \\ 2. REPORT TYPE \\ 3. DATES COVERED (From - To)}

01-10-2007

\section{TITLE AND SUBTITLE}

Technical Memorandum

Propulsion Health Management System Development for Affordable and Reliable Operation

of Space Exploration Systems

5a. CONTRACT NUMBER

5b. GRANT NUMBER

5c. PROGRAM ELEMENT NUMBER

\section{AUTHOR(S)}

Melcher, Kevin, J.; Maul, William, A.; Garg, Sanjay

\section{5d. PROJECT NUMBER}

5e. TASK NUMBER

5f. WORK UNIT NUMBER

WBS 136905.08.05.07.01.03

\section{PERFORMING ORGANIZATION NAME(S) AND ADDRESS(ES)}

National Aeronautics and Space Administration

\section{PERFORMING ORGANIZATION}

REPORT NUMBER

John H. Glenn Research Center at Lewis Field

E-16214

Cleveland, Ohio 44135-3191

\section{SPONSORING/MONITORING AGENCY NAME(S) AND ADDRESS(ES)}

National Aeronautics and Space Administration

Washington, DC 20546-0001

$\begin{aligned} & \text { 10. SPONSORING/MONITORS } \\ & \text { ACRONYM(S) } \\ & \text { NASA }\end{aligned}$
$\begin{aligned} & \text { 11. SPONSORING/MONITORING } \\ & \text { REPORT NUMBER } \\ & \text { NASA/TM-2007-215034; AIAA-2007- } \\ & 6237\end{aligned}$

\section{DISTRIBUTIONIAVAILABILITY STATEMENT}

Unclassified-Unlimited

Subject Categories: 20 and 12

Available electronically at http://gltrs.grc.nasa.gov

This publication is available from the NASA Center for AeroSpace Information, 301-621-0390

\section{SUPPLEMENTARY NOTES}

\section{ABSTRACT}

The constraints of future Exploration Missions will require unique integrated system health management capabilities throughout the mission. An ambitious launch schedule, human-rating requirements, long quiescent periods, limited human access for repair or replacement, and long communication delays, all require an integrated approach to health management that can span distinct, yet interdependent vehicle subsystems, anticipate failure states, provide autonomous remediation and support the Exploration Mission from beginning to end. Propulsion is a critical part of any space exploration mission, and monitoring the health of the propulsion system is an integral part of assuring mission safety and success. Health management is a somewhat ubiquitous technology that encompasses a large spectrum of physical components and logical processes. For this reason, it is essential to develop a systematic plan for propulsion health management system development. This paper provides a high-level perspective of propulsion health management systems, and describes a logical approach for the future planning and early development that are crucial to planned space exploration programs. It also presents an overall approach, or roadmap, for propulsion health management system development and a discussion of the associated roadblocks and challenges. 15. SUBJECT TERMS

Health management; Sensor selection; Data validation; Fault detection; Fault isolation; Information fusion; Verification and validation

\begin{tabular}{|c|c|c|c|}
\hline \multicolumn{3}{|c|}{ 16. SECURITY CLASSIFICATION OF: } & \multirow{2}{*}{$\begin{array}{l}\text { 17. LIMITATION OF } \\
\text { ABSTRACT } \\
\text { UU }\end{array}$} \\
\hline $\begin{array}{l}\text { a. REPORT } \\
\text { U }\end{array}$ & $\begin{array}{l}\text { b. ABSTRACT } \\
\text { U }\end{array}$ & $\begin{array}{l}\text { c. THIS } \\
\text { PAGE } \\
\text { U }\end{array}$ & \\
\hline
\end{tabular}

18. NUMBER
OF
PAGES
18

19a. NAME OF RESPONSIBLE PERSON
STI Help Desk (email:help@sti.nasa.gov)
19b. TELEPHONE NUMBER (include area code)
301-621-0390

Standard Form 298 (Rev. 8-98) Prescribed by ANSI Std. Z39-18 

